\title{
Determination of triterpenoids, carotenoids, chlorophylls, and antioxidant capacity in Allium ursinum L. at different times of harvesting and anatomical parts
}

\author{
Sabina Lachowicz ${ }^{1} \cdot$ Jan Oszmiański ${ }^{1} \cdot$ Rafał Wiśniewski $^{2}$
}

Received: 27 November 2017 / Revised: 9 January 2018 / Accepted: 20 January 2018 / Published online: 10 February 2018

(c) The Author(s) 2018. This article is an open access publication

\begin{abstract}
Triterpenoids, carotenoids, chlorophylls, and antioxidant capacity of individual parts of wild garlic at different times of harvesting were studied. Leaves, flowers, bulbs, and stems of Allium ursinum were used in this study. The contents of triterpenoids, carotenoids, and chlorophylls were determined by UPLC-PDA-Q/TOF-MS, and the antioxidant capacity was determined by ABTS and FRAP assay. A total of 21 compounds including 3 triterpenoids, 11 carotenoids, and 7 chlorophylls were identified in anatomical parts of A. ursinum in March and June 2016. These compounds present in individual anatomical parts of wild garlic were determination in this study for the first time ever. The average content of total triterpenoids ranged from 750.7 to $4159.5 \mathrm{mg} / \mathrm{kg}$ dry matter $(\mathrm{dm})$ and that of carotenoids and chlorophylls ranged from 14.4 to $14,424.5 \mathrm{mg} / \mathrm{kg}$ $\mathrm{dm}$ for bulbs and leaves. The average level of the antioxidant capacity ranged from 37.1 to $91.7 \mu \mathrm{mol}$ Trolox $/ \mathrm{g} \mathrm{dm}$ in bulbs and leaves, respectively. The leaves, flowers, and stems of wild garlic are a good source of health-promoting compounds. They can be used as functional food ingredients, dietary supplements, and additives.
\end{abstract}

Keywords Wild garlic · Leaves · Bioactive compounds · Isoprenoid compounds · UPLC-PDA-Q/TOF-MS

\section{Introduction}

Over the past few years, there has been growing interest in alternative plants, which can be a source of active compounds in the treatment and prevention of diseases such as metabolic cancer, stroke and coronary diseases. Such plants may include wild garlic, which is a valuable component in the human diet. The compounds of wild garlic have potent biological activity [1]. It is used as a spice in the cuisines of many nations, and it has been used for centuries in medicine. The leaves of wild garlic are edible and can be used boiled as a vegetable, as a salad, or as an ingredient for pesto. The stems and bulbs are also edible and highly palatable $[2,3]$.

Sabina Lachowicz

sabina.lachowicz@upwr.edu.pl

1 Department of Fruit, Vegetable and Plant Nutraceutical Technology, Faculty of Biotechnology and Food Science, Wrocław University of Environmental and Life Science, 37 Chełmońskiego Street, 51-630 Wrocław, Poland

2 Department of Food Technology and Human Nutrition, Faculty of Biology and Agriculture, Rzeszow University, Zelwerowicza 4 Street, 35-601 Rzeszow, Poland
The growing period of garlic begins in early spring and ends at the beginning of summer. During this period, changes in the contents of active compounds and pigment in various parts of the plant occur [3].

Wild garlic is reach sources of dietary compounds, especially flavonoids (kaempferol), which include important bioactive compounds $[4,5]$. Health benefits of phenolic compounds derive from their antitumor, antioxidant, antithrombotic, and anti-inflammatory properties $[3,6]$. Polyphenols are located in all parts of plants, including leaves, stems, roots, fruits, and flowers [7]. Other compounds present in garlic and having health benefits are triterpenoids, chlorophylls, and carotenoids. Triterpenes are a very big group of compounds and are present in a wide variety of dicotyledonous plant species. Triterpenoids exhibit many biological activities such as antifungal, antibacterial, antiviral, antiprotozoal, and anti-inflammatory [4]. Triterpenoids - derivatives of triterpenes such as oleanolic, ursolic, or betulinic acids-are mainly located in cuticular waxes [8].

The color of Allium ursinum is due to chlorophylls and carotenoids, which are natural dyes and are located in the chloroplasts of leaves. They are used primarily in the food industry for coloring foods. Chlorophylls are responsible for 
the yellow-green and blue-green color. These pigments are subject to degradation during various processes. Chlorophyll has antioxidant properties, can help prevent degenerative diseases, and has anticancer and antimutagenic effects [9, 10]. In contrast, carotenoids are responsible for the orange, red, and yellow color of plants. Degradation of the pigments is affected by light, and oxygen influences the deterioration of flavor and color of products [9-12]. The antioxidant capacity of carotenoids is used in scavenging of free radical and counteracting oxidation, consequently reducing the risk of cardiovascular, acute inflammation problems, and UV light damage [7].

Natural compounds in wild garlic can be used as health food, functional food, and dietary supplements in the pharmaceutical industry. There have been no previous studies on the influence of maturity stage on triterpenoids, carotenoids, and chlorophylls profile and antioxidant capacity in $A$. ursinum. Therefore, the present work evaluated antioxidant capacity and bioactive compounds in wild garlic in different anatomical parts (leaves, stems, bulbs, and flowers) collected in March and June. Leaves, stems, roots, and flowers were determined for concentration of carotenoids, chlorophylls, and triterpenoids with UPLC-PDA-Q/TOF-MS.

\section{Materials and methods}

\section{Reagents and standards}

ABTS [2,2'-azinobis-(3-ethylbenzothiazoline-6-sulfonic acid)], Trolox (6-hydroxy-2,5,7,8-tetramethylchroman2-carboxylic acid), TPTZ (2,4,6-tri(2-pyridyl)-s-triazine), acetonitrile, formic acid, methanol all-trans- $\beta$-carotene, alltrans-lutein, $\alpha$-carotene, neoxanthin, antheraxanthin, violaxanthin, $\beta$-cryptoxanthin, chlorophyll $a$, oleanolic, betulinic, and ursolic acid were purchased from Sigma-Aldrich (Steinheim, Germany).

\section{Plant materials}

The raw material used in this study comprised bulbs, leaves, flowers, and stems of $A$. ursinum L. Plants were obtained in March and June 2016 and were collected from the forest area near Rzeszów, Poland, (5000'46"N 21 59'39"E). In each growing period, 100 plants were collected, and various morphological parts were separated. The individual anatomical parts were directly frozen in liquid nitrogen and freeze-dried (24 h; Christ Alpha 1-4 LSC; Germany). The homogeneous dry material was obtained by crushing the dried tissues using a closed laboratory mill (IKA A.11, Germany). The powders were kept in a freezer $\left(-80^{\circ} \mathrm{C}\right)$ until $24 \mathrm{~h}$ before extract preparation.

\section{Identification and quantification of carotenoids and chlorophylls by the UPLC-PDA-MS/MS method}

Sample extraction was performed as described by Lachowicz et al. [13]. Freeze-dried different parts of wild garlic $(\sim 0.35 \mathrm{~g})$ were mixed with $5 \mathrm{~mL}$ of hexane:acetone:methanol $(2: 1: 1)$, shaken at $20^{\circ} \mathrm{C}$ for $30 \mathrm{~min}$ and $40 \mathrm{kHz}$. Next, the slurry was centrifuged at $19,000 \mathrm{~g}$ for $10 \mathrm{~min}$, and the supernatant was evaporated to dryness. The pellet was re-extracted using $2 \mathrm{~mL}$ of $100 \%$ methanol, filtered through a hydrophilic PTFE $0.20 \mu \mathrm{m}$ membrane (Millex Simplicity Filter, Merck, Darmstadt, Germany), and used for analysis.

For the extraction of carotenoids, a protocol similar to that described earlier was followed [14]. Compounds were separated with an ACQUITY UPLC BEH RP C18 column $(1.7 \mu \mathrm{m}, 2.1 \mathrm{~mm} \times 100 \mathrm{~mm}$, Waters Corp., Milford, MA, USA) at $32{ }^{\circ} \mathrm{C}$. The elution solvents were $\mathrm{ACN}: \mathrm{MeOH}$ $(7: 3, \mathrm{v} / \mathrm{v})(\mathrm{A})$ and $0.1 \%$ formic acid (B). Samples $(10 \mu \mathrm{L})$ were eluted according to the linear gradient described by Delphino-Rius et al. [15]. The runs were monitored at 450 and $650 \mathrm{~nm}$. The PDA spectra were measured over the wavelength range of $200-700 \mathrm{~nm}$ in steps of $2 \mathrm{~nm}$. The retention times and spectra were compared to those of the authentic standards. All incubations were done in triplicate. The results were expressed as milligram per kilogram of dry matter $(\mathrm{mg} / \mathrm{kg} \mathrm{dm})$.

\section{Identification and quantification of triterpenoids by the UPLC-PDA-MS/MS method}

Samples' extraction were performed as described by Farneti et al. [16]. The powder samples $(\sim 0.5 \mathrm{~g})$ were extracted with $5 \mathrm{~mL}$ of ethyl acetate and $5 \mathrm{~mL}$ of hexane. The extraction was performed by incubation for $20 \mathrm{~min}$, $20{ }^{\circ} \mathrm{C}, 40 \mathrm{kHz}$ under sonication (Sonic 6D, Polsonic, Warsaw, Poland) with occasional shaking. After the first extraction, the samples were kept at $4{ }^{\circ} \mathrm{C}$ overnight. On the next day, the samples were re-extracted in the same conditions. Next, the slurry was centrifuged at $19,000 \mathrm{~g}$ for $10 \mathrm{~min}$, and the supernatant was evaporated to dryness. The pellet was re-extracted using $2 \mathrm{~mL}$ of $100 \%$ methanol, filtered through a hydrophilic PTFE $0.20 \mu \mathrm{m}$ membrane (Millex Simplicity Filter, Merck, Darmstadt, Germany) and used for analysis. Identification and quantification of ursolic, oleanolic, and betulinic acids were done using the ACQUITY Ultra Performance LC system with a binary solvent manager (Waters Corp., Milford, MA, USA), a UPLC BEH C18 column $(1.7 \mu \mathrm{m}, 2.1 \mathrm{~mm} \times 150 \mathrm{~mm}$, Waters Corp., Milford, MA, USA), and a Q-TOF mass spectrometer (Waters, Manchester, UK) equipped with an 
electrospray ionization (ESI) source, operating in negative mode. The elution solvents were $100 \%$ methanol (A) and $100 \%$ acetonitrile (B) (15:85, v/v). Ursolic, oleanolic, and betulinic acids were eluted isocratically at a flow rate of $0.1 \mathrm{~mL} / \mathrm{min}$ for $10 \mathrm{~min}$ at $20{ }^{\circ} \mathrm{C} . \mathrm{m} / \mathrm{z}$ for betulinic acid was 455.34, for oleanolic acid 455.34, and for ursolic acid 455.33, and the retention times were 6.89, 7.11, and $7.59 \mathrm{~min}$, respectively. The compounds were monitored at $210 \mathrm{~nm}$. All data were obtained in triplicate. The results were expressed as milligram per kilogram of dry matter $(\mathrm{mg} / \mathrm{kg} \mathrm{dm})$.

\section{Determination of antioxidant capacity}

The samples for analysis were prepared as described previously by Lachowicz et al. [13]. Freeze-dried fruits $(0.5 \mathrm{~g})$ were mixed with $10 \mathrm{~mL}$ of $\mathrm{MeOH} /$ water $(80: 20 \%$, v/v) $+1 \%$ $\mathrm{HCl}$, sonicated at $20^{\circ} \mathrm{C}$ for $15 \mathrm{~min}$, and left for $24 \mathrm{~h}$ at $4{ }^{\circ} \mathrm{C}$. Then, the extract was again sonicated for $15 \mathrm{~min}$, and centrifuged at $15,000 \mathrm{~g}$ for $10 \mathrm{~min}$.

The ABTS radical scavenging activity and ferric reducing antioxidant power (FRAP) methods were also used as described by Re et al. [17] and Benzie and Strain [18], respectively. Briefly, $10 \mu \mathrm{L}$ of the supernatant was mixed with $990 \mu \mathrm{L}$ of ABTS or FRAP. After 10 min of reaction, the absorbance was measured at $734 \mathrm{~nm}$ for ABTS and $593 \mathrm{~nm}$ for FRAP. Determinations by the ABTS and FRAP methods were performed using the UV-2401 PC spectrophotometer (Shimadzu, Kyoto, Japan). The antioxidant activity was expressed as micro mol of Trolox per gram of dry matter ( $\mu \mathrm{mol}$ Trolox/g dm).

\section{Statistical analysis}

Statistical analysis, one-way ANOVA, and principal component analysis (PCA) were conducted using Statistica version 12.5 (StatSoft, Kraków, Poland). Significant differences between mean values were evaluated by one-way ANOVA and Duncan's multiple range test.

\section{Results and discussion}

\section{Identification and quantification of triterpenoids in different parts of wild garlic}

The samples' extracts from different parts of wild garlic in different maturity stages were analyzed by the LC-PDA-ESI-MS/MS system. Results of qualitative analysis obtained by the UPLC with a PDA detector and FL are presented in Table 1 and Fig. 1. The detected compounds were identified as betulinic, oleanolic, and ursolic acids were based on the comparison of their retention times (Rt),

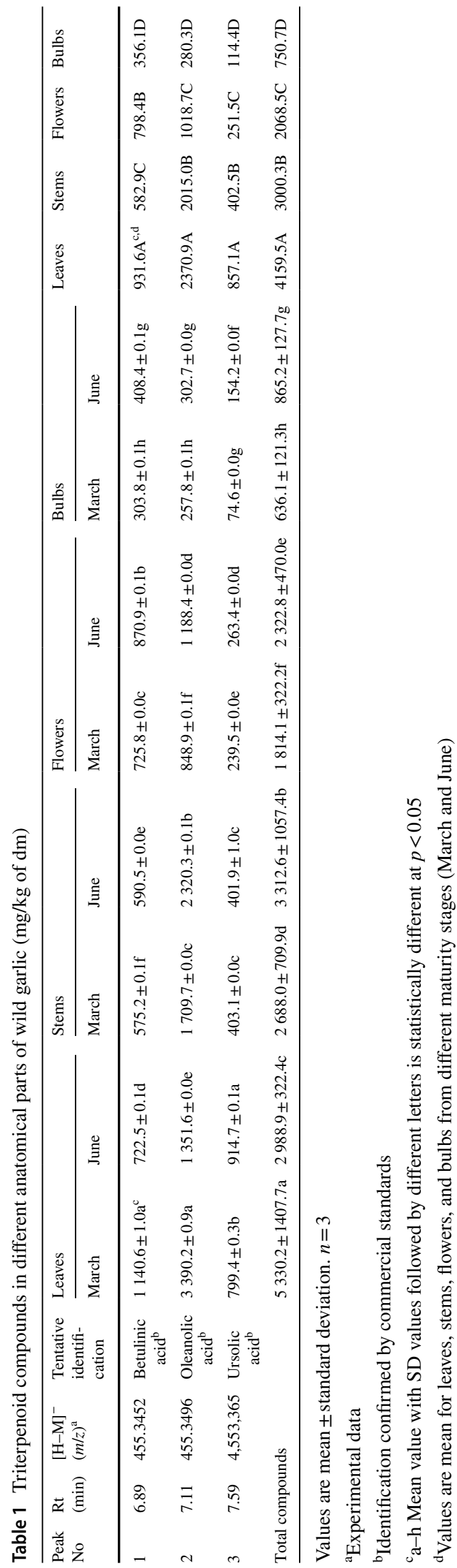




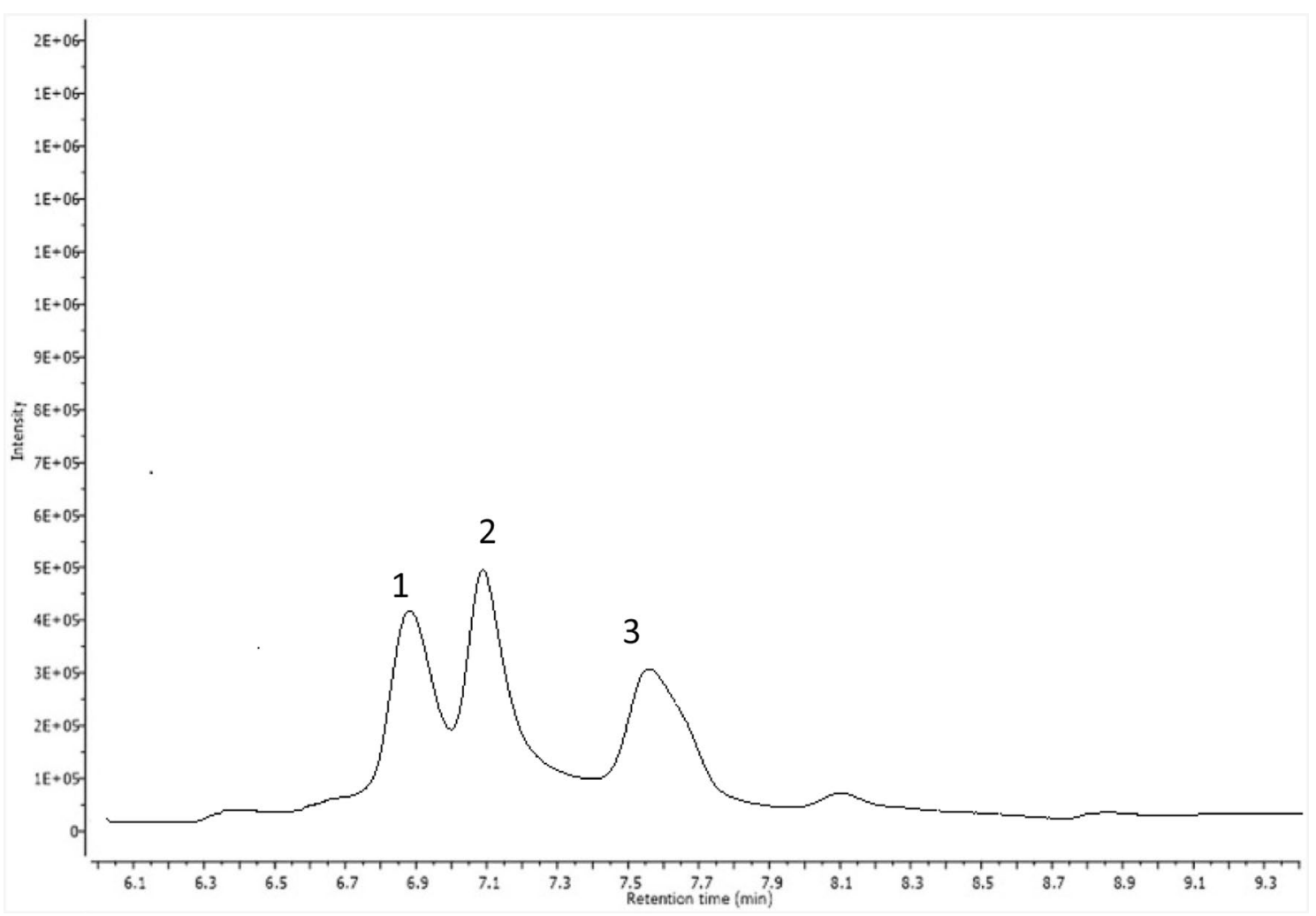

Fig. 1 Segment from 6.00 to $9.00 \mathrm{~min}$ of triterpenoids LC-DAD chromatogram at $210 \mathrm{~nm}$ of leaves of wild garlic from June. (1) Betulinic acid; (2) oleanolic acid; (3) ursolic acid

MS, and MS/MS data with those of standards, if available [19-21]. To identify the three compounds, negative ionization was used. Betulinic, oleanolic, and ursolic acids have not been determined in whole plant of wild garlic (A. ursinum) and its morphological parts so far.

The triterpenoids content in the wild garlic at different maturity stages varied depending on the parts of the plant: the lowest concentration was in bulbs from March $(636.1 \mathrm{mg} / \mathrm{kg} \mathrm{dm})$ to June $(26.5 \%$ more $)<$ flowers from March ( $1814.1 \mathrm{mg} / \mathrm{kg} \mathrm{dm})$ to June ( $22 \%$ more) < stems from March $(2688 \mathrm{mg} / \mathrm{kg} \mathrm{dm})$ to June (19\% more), and the highest was observed in leaves from March $(5330.2 \mathrm{mg} / \mathrm{kg} \mathrm{dm}$ ) to June ( $44 \%$ less). A decrease in the content of triterpenoid compounds in the leaves may be due to changes in the plant and its various parts during maturation or maturity of leaves from June (too mature). Perhaps, the content of triterpenes, probably like chlorophylls, during maturity could reach the maximum concentration and then was a decrease in the content of triterpenoids in the leaves of wild garlic. In addition, the difference on the content of triterpenes in leaves collected in June and March was likely due to the weakening of the wax layer on the leaf surface during ripening and consequently the reduction of the content of these compounds in leaves collected in June [22]. Notwithstanding, the results of chromatographic analysis coupled with a statistical test (Table 1) showed that the leaves were not only a valuable source of bioactive compounds, but most of all contained significantly more triterpenoids than the stems, flowers, and bulbs. However, although, in the bulbs, betulinic acid was a more abundant triterpenes than ursolic and oleanolic acid, the dominant triterpenoid compound of the different anatomical parts (except bulbs) of wild garlic was oleanolic acid. The average content of oleanolic acids ranged from $280.3 \mathrm{mg} / \mathrm{kg} \mathrm{dm}$ in the bulbs to $2370.9 \mathrm{mg} / \mathrm{kg} \mathrm{dm}$ in the leaves. The other triterpenoid compounds were betulinic acid (from $356.1 \mathrm{mg} / \mathrm{kg} \mathrm{dm}$ in the bulbs to $931.6 \mathrm{mg} / \mathrm{kg}$ $\mathrm{dm}$ in the leaves) and ursolic acid (from $114.4 \mathrm{mg} / \mathrm{kg} \mathrm{dm}$ in the bulbs to $857.1 \mathrm{mg} / \mathrm{kg} \mathrm{dm}$ in the leaves). The average total content of triterpenoid compounds contained in stems, flowers, and bulbs was found to be 1.4, 2.0, and 5.5 times lower, respectively, than that in leaves. However, It may be observed that, with the increase of the plant, the average content of triterpenoids was higher in June than that at the first stages of maturity. Caligiani et al. [23], researching botanical extracts sold as herbal and food product ingredients, identified betulinic, oleanolic, and ursolic acids. The content of oleanolic and ursolic acids in Arctostaphylos uva-ursi L. leaves were 4.8 times lower and 1.2 times higher, respectively, than in the leaves of wild garlic in our research. However, the content of betulinic and oleanolic 
acids in Lagerstroemia speciosa L. leaves was 4.1 and 2.9 times lower, respectively, than in the leaves of wild garlic, but the content of ursolic acid was 2.5 times higher. The content of betulinic, oleanolic, and ursolic acids was 9.9 times lower and 2.3 and 16.6 times higher, respectively, compared to the wild garlic flowers. The differences in the content of triterpenoids may among others be due to different methods of their determination, type and composition of soil, environmental factors, and stress. Kolniak-Ostek [19] in their studies of different anatomical parts of pear identified three acids. The content in pear leaves was 1.3 times lower that the leaves in wild garlic. Different contents of bioactive compounds are due, for example, to the different materials analyzed. The content of triterpenoids depends on many factors, for example, degree of maturity at harvest and environmental conditions [24]. Triterpenoids are known for their anticancer, anti-inflammatory, and antioxidant properties. They were also reported to protect plants against microbial attacks [25] (Fig. 1).

\section{Determination of chlorophylls and carotenoids in anatomical parts of wild garlic}

Identification and quantification of 18 compounds belonging to chlorophylls (7) and carotenoids (11) were based on a comparison of their retention times (Rt) and MS and MS/MS data with available standards and published data. The identification and concentration carotenoids and chlorophylls results are presented in Table 2.

\section{Carotenoids}

The carotenoids were determined based on the UV spectra, retention times, and comparison of their MS and MS/MS data with available standards and literature data [26-31].

Peaks 1 and 2 (Rt 2.95, $3.55 \mathrm{~min}$ ), which showed a molecular ion at $\mathrm{m} / \mathrm{z} 601$ and fragmentation at $\mathrm{m} / \mathrm{z} 583,565,221$, and 181 , were identified as neoxanthin and violaxanthin [32, 33]. Peak 5 (Rt $5.21 \mathrm{~min}$ and $\lambda_{\max } 267,445$, and 474), which showed an ion at $\mathrm{m} / z 568$ and MS/MS fragments at $\mathrm{m} / z 551$ and 553, was identified as all-trans-lutein, consistent with the authentic standard, wavelengths of absorbance maxima, and literature data $[31,34]$. Peak 7 (Rt $5.85 \mathrm{~min}$ and $\lambda_{\max }$ $335,420,446$, and 474) was identified as 13-cis-lutein, with $[\mathrm{M}-\mathrm{H}]^{+}$at $\mathrm{m} / \mathrm{z}, 568$ and fragmentation MS/MS ion at $\mathrm{m} / \mathrm{z} 551$ and 553 [27, 29, 34] Peaks 8 and 10 (Rt 7.45 and 7.77 min, and $\lambda_{\max } 454,481$ ), with $[\mathrm{M}-\mathrm{H}]^{+}$at $m / z 553$ and fragmentation at $m / z 461$ and 119 , were identified as $\alpha$-cryptoxanthin and $\beta$-cryptoxanthin. These compounds were consistent with authentic standards, wavelengths of absorbance maxima, and literature data [26, 30, 34]. Peaks 12-16 (Rt 8.79, 8.92, 9.00, 9.08 , and $9.12 \mathrm{~min}$ ) were identified as $\alpha$-carotene and isomer $\beta$-carotene, based on the $[\mathrm{M}-\mathrm{H}]^{+}$characteristic molecular ion at $\mathrm{m} / \mathrm{z}$ 537, and characteristic fragments at $\mathrm{m} / \mathrm{z} 445$ [30, $31,34]$. The presence of all-trans- $\beta$-carotene was confirmed by co-elution with an authentic standard. The main compounds included 9 -cis- $\beta$-carotene, 13 -cis- $\beta$-carotene, and 15 -cis- $\beta$-carotene, all with $[\mathrm{M}+\mathrm{H}]^{+}$at $m / z=537$. These compounds were identified by their characteristic UV-Vis spectrum and chromatographic preserve relative to the other geometrical isomers of carotene [34-36] (Table 3).

The total content of carotenoids in A. ursinum leaves from June was over 1.4 times higher with respect to the leaves from March $(9142.3$ and $6550.5 \mathrm{mg} / \mathrm{kg} \mathrm{dm}$, respectively) (Table 3 and Fig. 2). The content of carotenoids in stems from June $(853.1 \mathrm{mg} / \mathrm{kg} \mathrm{dm})$ was almost 1.6 times higher than in stems from March. Leaves from June contained 1.6 times more carotenoid compounds compared to the flowers from March. In bulbs from June, $6.8 \mathrm{mg} / \mathrm{kg}$ of carotenoids was detected, while only $5.7 \mathrm{mg} / \mathrm{kg} \mathrm{dm}$ was found in bulbs from March. Among 11 identified carotenoids, 5 were dominant. They were: $\operatorname{trans}$ - $\beta$-carotene (from $3262.7 \mathrm{mg} / \mathrm{kg} \mathrm{dm}$ in the leaves to $3.3 \mathrm{mg} / \mathrm{kg} \mathrm{dm}$ in the bulbs); all-trans-lutein (from $1287.6 \mathrm{mg} / \mathrm{kg} \mathrm{dm}$ in the leaves to $0.8 \mathrm{mg} / \mathrm{kg} \mathrm{dm}$ in the bulbs); $\alpha$-cryptoxanthin (from $1133.6 \mathrm{mg} / \mathrm{kg} \mathrm{dm}$ in the leaves to $93.1 \mathrm{mg} / \mathrm{kg} \mathrm{dm}$ in the stems); 9 -cis- $\beta$-carotene (from $703.2 \mathrm{mg} / \mathrm{kg} \mathrm{dm}$ in the leaves to $0.9 \mathrm{mg} / \mathrm{kg} \mathrm{dm}$ in the bulbs); and $\beta$-cryptoxanthin (from $582,0 \mathrm{mg} / \mathrm{kg} \mathrm{dm}$ in the leaves to $0.6 \mathrm{mg} / \mathrm{kg} \mathrm{dm}$ in the bulbs). The average total carotenoid contents ranged from 7846.4 to $6.2 \mathrm{mg} / \mathrm{kg} \mathrm{dm}$ for the leaves and bulbs, respectively. The average total carotenoid content in stems, flowers, and bulbs was found to be $11.4,7.5$, and 1265.5 times lower, respectively, than that in leaves. The content of identified compounds was higher after collection in June than that in March.

Various amounts of different carotenoids have been reported previously in vegetables and fruits [30]. The content of carotenoids in carrot was $9856 \mathrm{mg} / \mathrm{kg} \mathrm{dm}$, in grapefruit $266.5 \mathrm{mg} / \mathrm{kg} \mathrm{dm}$, in spinach $5224.5 \mathrm{mg} / \mathrm{kg} \mathrm{dm}$, and in sweet potato $61.8 \mathrm{mg} / \mathrm{kg} \mathrm{dm} \mathrm{[30].} \mathrm{The} \mathrm{results} \mathrm{were} \mathrm{varied;}$ the carotenoid content observed in the wild garlic was higher than the content in grapefruit, but lower than the content in carrots and spinach. Saini et al. [28], in studies on the contents of carotenoids in selected vegetables, reported $2386.2 \mathrm{mg} / \mathrm{kg} \mathrm{dm}$ in spinach, $1691.5 \mathrm{mg} / \mathrm{kg}$ in coriander leaves, $1092.6 \mathrm{mg} / \mathrm{kg} \mathrm{dm}$ in fenugreek, $46.5 \mathrm{mg} / \mathrm{kg}$ in broccoli, and $39.5 \mathrm{mg} / \mathrm{kg}$ in Brussels sprouts.

\section{Chlorophylls}

Peak 3 (Rt $4.08 \mathrm{~min}$, and $\lambda_{\max } 411,653$ ) was identified as pheophorbide, showing a molecular ion $[\mathrm{M}+\mathrm{H}]^{+}$at $\mathrm{m} / z$ 593, and a fragment ion at $m / z 533$, which is consistent with the authentic standard, wavelengths of absorbance maxima and literature data [37]. Peak 4 (Rt $4.92 \mathrm{~min}$, and $\lambda_{\max } 443,601$ ) 


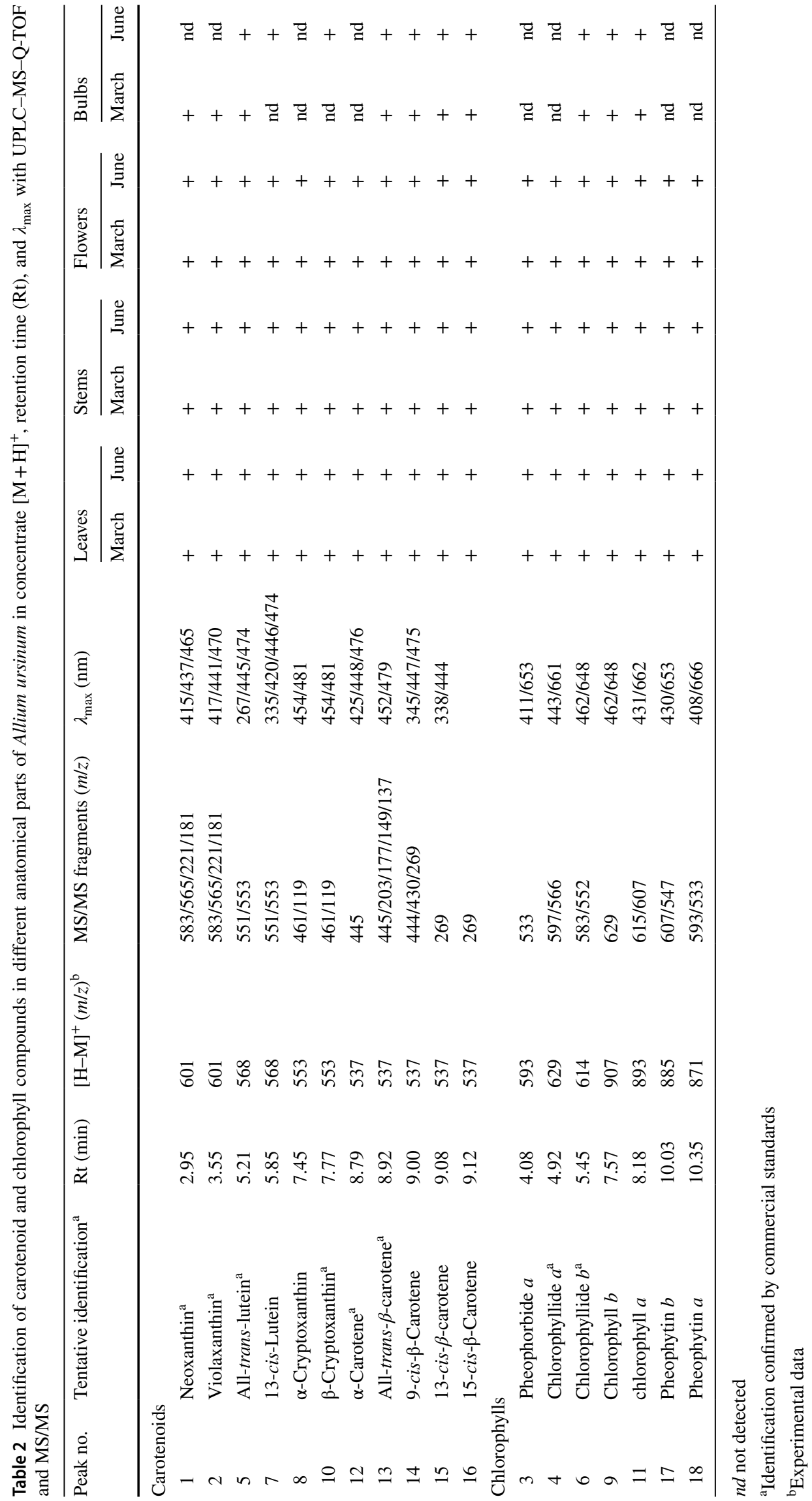




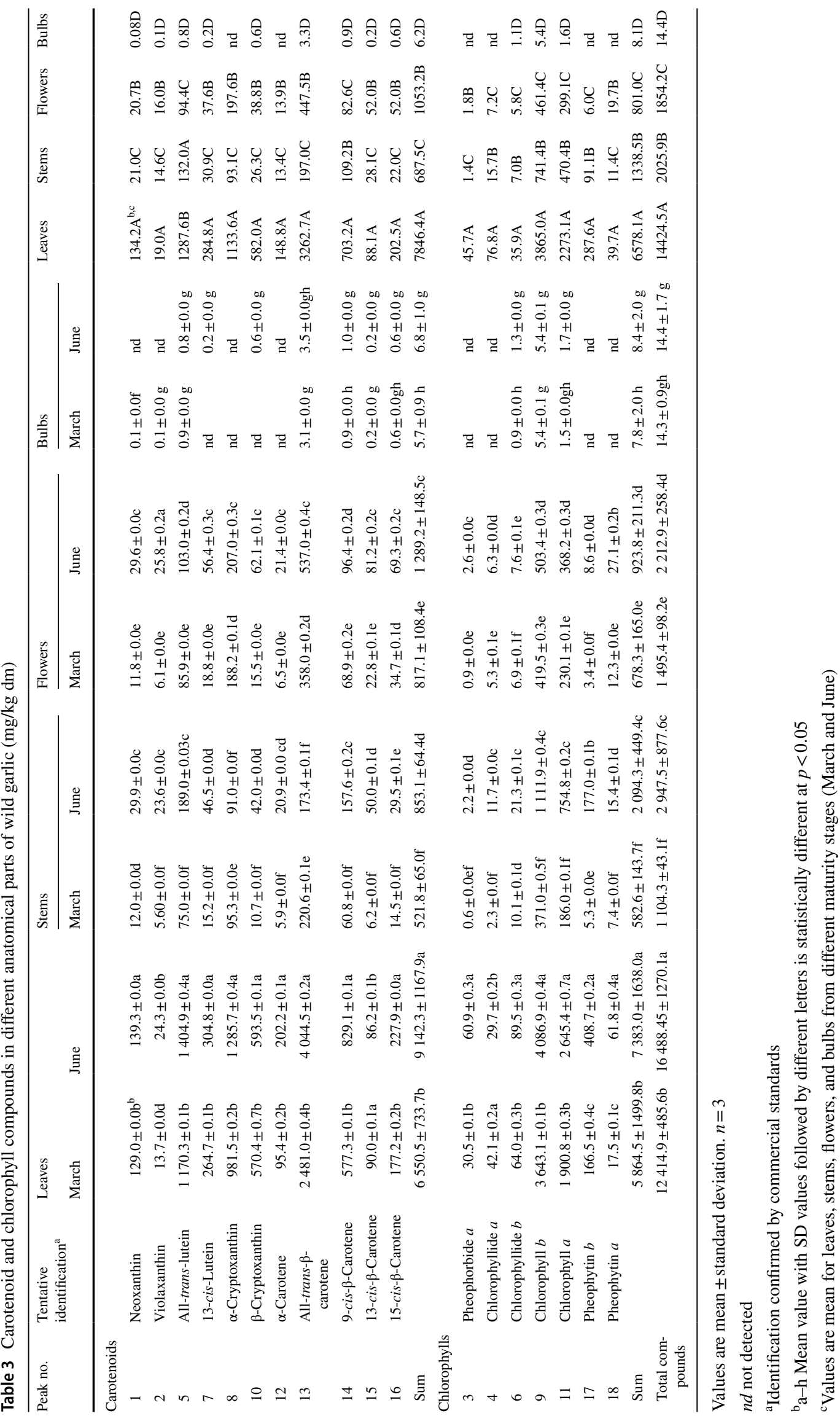




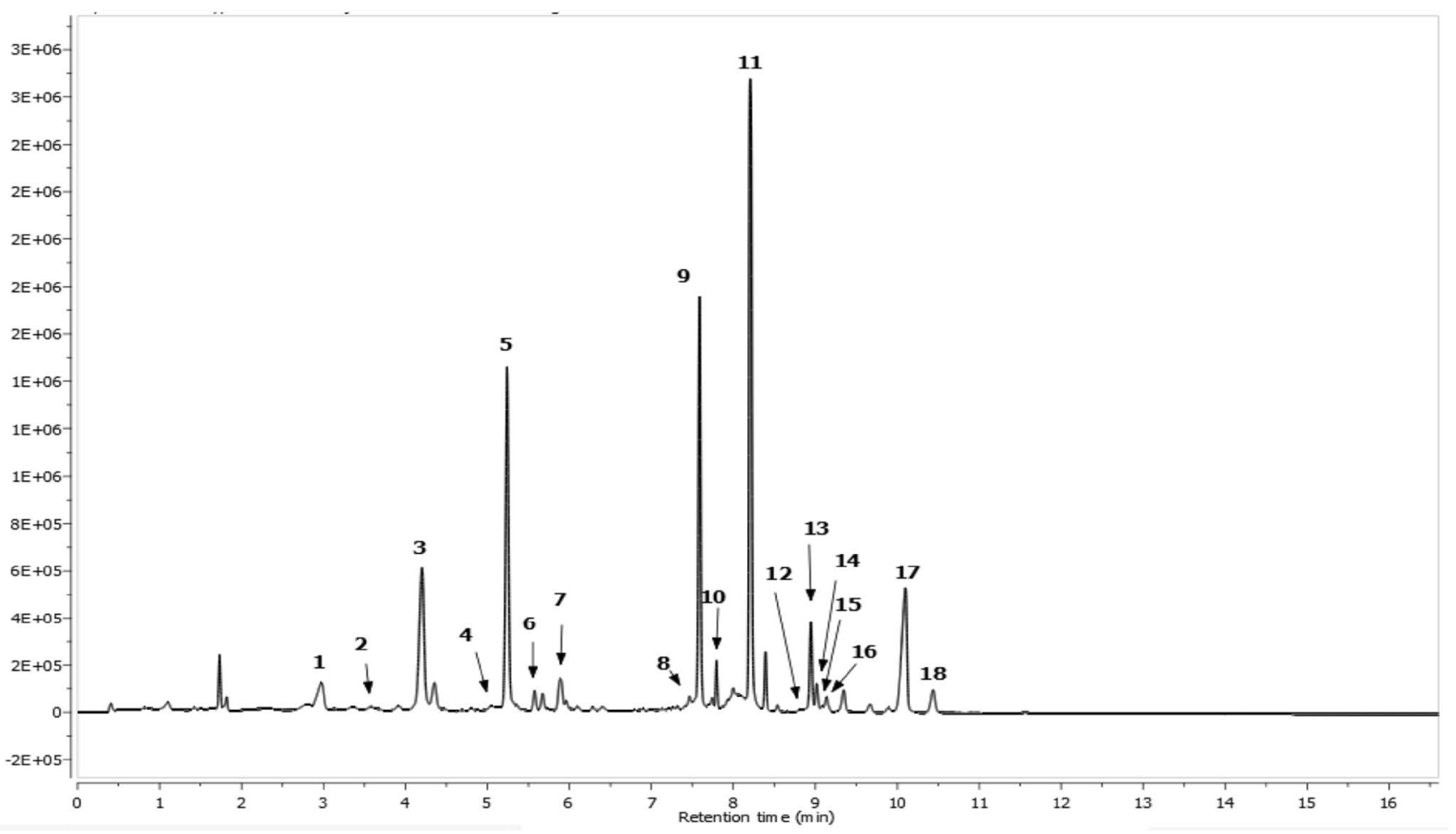

Fig. 2 Segment from 2.50 to $10.50 \mathrm{~min}$ of carotenoids LC-DAD chromatogram at $450 \mathrm{~nm}$ of leaves of wild garlic from June. (1) Neoxanthin; (2) violaxanthin; (3) pheophorbide $a$; (4) chlorophyllide $b$; (5) all-trans-Lutein; (6) chlorophyllide $a$; (7) 13-cis-lutein;

had a molecular ion at $m / z 629$ and MS/MS fragment ion at $m / z 597$ and 566, suggesting that this chlorophyll was chlorophyllide $a[31,37]$. Peak 6 (Rt $5.45 \mathrm{~min}$ and $\lambda_{\max } 462$, 648 ) assigned to chlorophyllide $b$ showed a molecular ion $[\mathrm{M}+\mathrm{H}]^{+}$at $m / z 614$, and a fragment ion at $m / z 583$ and 552 [37, 38]. Peaks 9 (Rt 7.57 min, and $\lambda_{\max } 462,648$ ) was identified as chlorophyll $b$, which showed an ion $[\mathrm{M}+\mathrm{H}]^{+}$ at $m / z$ 907, and fragmentation MS/MS at $m / z$ 629, which is consistent with the wavelengths of absorbance maxima, literature data [31, 37], and the authentic standard. Peak 11 (Rt $8.18 \mathrm{~min}, \lambda_{\max } 431,662$ ) was identified as chlorophyll $a$, which showed an intense ion peak at $m / z$ 893, and fragment ions at $\mathrm{m} / z, 615$ and 607. Peak 17 (Rt $10.03 \mathrm{~min}$, and $\lambda_{\max }$ $430,653)$, with $[\mathrm{M}+\mathrm{H}]^{+}$at $\mathrm{m} / \mathrm{z} 885$ and fragmentation ions MS/MS at $m / z 607$ and 547, was identified as pheophytin $b$, which is consistent with literature data [37, 39] and wavelengths of absorbance maxima. Peak 18 (Rt $10.35 \mathrm{~min}$, and $\left.\lambda_{\max } 408,666\right)$ had a molecular ion $[\mathrm{M}+\mathrm{H}]^{+}$at $\mathrm{m} / z, 871$ and a fragment ion $\mathrm{m} / \mathrm{z} 593$ and 533, thus indicating that this compound was pheophytin $a$ [37] (Table 3).

The total content of chlorophylls in different parts of $A$. ursinum leaves from June was over 1.3 times higher with respect to the leaves from March (Table 3 and Fig. 2). The content of chlorophylls in other parts of the plant was as
(8) $\alpha$-cryptoxanthin; (9) chlorophyll $b$; (10) $\beta$-cryptoxanthin; (11) chlorophyll $a$; (12) $\alpha$-carotene; (13) all-trans $\beta$-carotene; (14) 9-cis$\beta$-carotene; (15) 13-cis- $\beta$-carotene; (16) 15-cis- $\beta$-carotene; (17) pheophytin $b$; and (18) pheophytin $a$

follows: the lowest in the bulbs from March $(7.8 \mathrm{mg} / \mathrm{kg}$ $\mathrm{dm})$ to the bulbs from June (7\% more), then in flowers from March $(678.3 \mathrm{mg} / \mathrm{kg} \mathrm{dm})$ to June (27\% more), and then in stems from March $(582.6 \mathrm{mg} / \mathrm{kg} \mathrm{dm})$ to June ( $72 \%$ more). Among seven identified carotenoids, three were dominant: chlorophyll $b$ (from $5.4 \mathrm{mg} / \mathrm{kg} \mathrm{dm}$ in the bulbs to $3865.0 \mathrm{mg} /$ $\mathrm{kg} \mathrm{dm}$ in the leaves); chlorophyll $a$ (from $1.6 \mathrm{mg} / \mathrm{kg} \mathrm{dm}$ in the bulbs to $2273.1 \mathrm{mg} / \mathrm{kg} \mathrm{dm}$ in the leaves); and pheophytin $b$ (from $6.0 \mathrm{mg} / \mathrm{kg} \mathrm{dm}$ in the flowers to $287.6 \mathrm{mg} / \mathrm{kg} \mathrm{dm}$ in the leaves). The average content of chlorophyll compounds contained in stems, flowers, and bulbs was found to be 4.9, 8.3, and 815.7 times lower, respectively, than that in leaves. Anatomical parts of wild garlic were characterized by high contents of chlorophylls, which is indicative of fruit ripeness because the green color and chlorophylls were intensive.

Various amounts of different chlorophylls have been reported previously in vegetables and fruits [30, 32]. Stinco et al. [30], in studies on the content of chlorophylls of some vegetables and fruit, observed values of 48995.2, 162.8, and $4.6 \mathrm{mg} / \mathrm{kg} \mathrm{dm}$ in spinach, broccoli, and guava, respectively. The results were heterogeneous; the chlorophyll compound contents observed in wild garlic were higher than those in broccoli and guava, but lower compared to spinach. Lisiewska et al. [33] in studies on the concentration of 


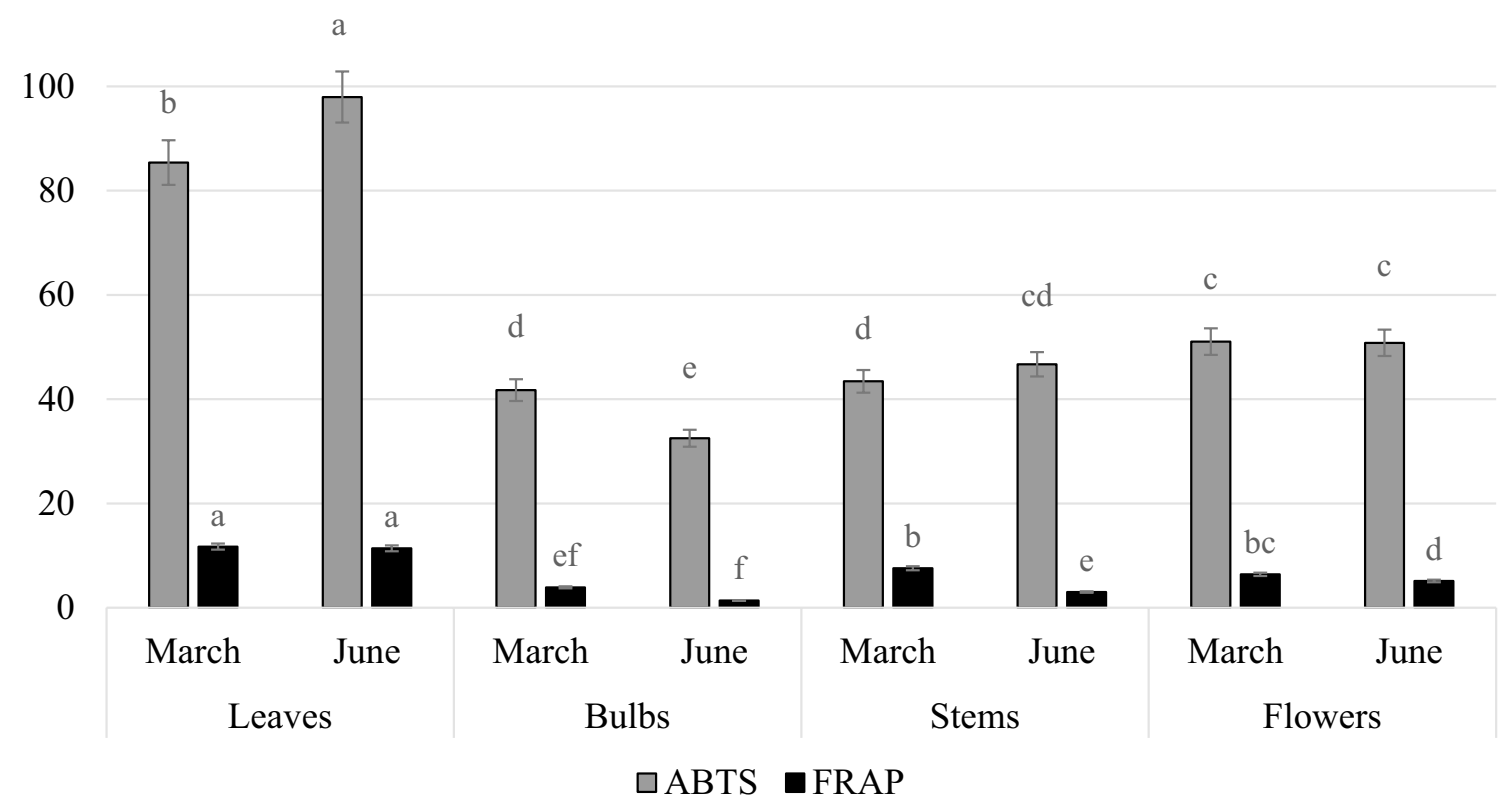

Fig. 3 Antioxidant capacity [ $\mu \mathrm{mol}$ Trolox/g dm] $]^{1,2}$ of different parts of wild garlic in different maturity stages. Number 1 indicates that values are means \pm standard deviation. $n=3$; Number 1 indicates that

chlorophylls in raw and frozen leaves and whole dill plants observed values of 130 and $77 \mathrm{mg} / \mathrm{kg}$, respectively.

The results for carotenoids and chlorophylls observed in fruit and vegetables are difficult to compare with our results due to differences between dry and fresh weight, different methods of determination applied, and different anatomical parts and whole materials.

The content of carotenoid and chlorophyll depends on the maturation stage and cultivar. Probably, the lower content of chlorophyll in the leaves of June may be due to mature leaves. The gradual increase of chlorophyll content along with the growth of the plant may be related to the changes that occur with the different parts of plants as well as the whole plant. During intensive growth, intensive synthesis and increased chlorophyll content are observed. Once the chlorophyll maximum content has been reached in the plant, than the chlorophyll content decomposes and gradually decreases. The results of the changes in the content of chlorophyll during the ripening of the plant are confirmed in the studies by Grey [40] and Mishra et al. [41]. The opposite is in the fruit, because during fruit ripening, the content of chlorophylls degraded and converted to colorless metabolites, and then carotenoids become perceptible, because that the low content of chlorophylls is indicative of fruit ripeness. Vegetables are a good source of chlorophylls compared to fruits [31, 33, 42]. Furthermore, A. ursinum leaves should be collected before the flowering period, i.e., from March to May. In time increase in plant, they become fibrous, hard. Acceptable level in intake of leaves ranges from 50 to $100 \mathrm{~g}$ a-f means \pm SD followed by different letters within the same line represent significant differences $(p<0.05)$

Table 4 Mean content of antioxidant capacity [ $\mu \mathrm{mol}$ Trolox/g dm] of different parts of wild garlic in different maturity stages

\begin{tabular}{llrrr}
\hline $\begin{array}{l}\text { Antioxidant } \\
\text { capacity }\end{array}$ & Leaves & Stems & Flowers & Bulbs \\
\hline ABTS & $91.7 \mathrm{aAb}$ & $37.1 \mathrm{D}$ & $45.1 \mathrm{C}$ & $50.9 \mathrm{~B}$ \\
FRAP & $11.7 \mathrm{~A}$ & $2.7 \mathrm{D}$ & $5.3 \mathrm{C}$ & $5.8 \mathrm{~B}$ \\
\hline
\end{tabular}

${ }^{\mathrm{a}}$ Values are mean for leaves, stems, flowers, and bulbs from different maturity stages (March and June)

${ }^{b} \mathrm{a}-\mathrm{f}$ Means \pm SD followed by different letters within the same line represent significant differences $(p<0.05)$

of fm per day. This is related to the fact that the plant contains a mild toxin — protoanemonin—which during drying or heating transforms into anemonin, a substance that is not toxic and has an analgesic effect $[39,43]$.

\section{Antioxidant capacity}

The results of the antioxidant capacity of parts of wild garlic in different maturity stages tested by the ABTS and FRAP assay are presented in Fig. 3 and Table 4. Statistical significant differences in the antioxidant properties were observed between measured parts (leaves, flowers, bulbs and roots) and between maturity stages using these assays. The average content of the antioxidant capacity, measured by the ABTS assay, in the parts of wild garlic ranged from 33.9 in bulbs to $83.7 \mu \mathrm{mol}$ Trolox/g dm in leaves, respectively. The average level of antioxidant capacity measured by FRAP 
assay in different parts of wild garlic ranged from 2.1 in bulbs to $9.0 \mu \mathrm{mol}$ Trolox $/ \mathrm{g} \mathrm{dm}$ in leaves. The level of antioxidant capacity (measured by ABTS and FRAP assay) in leaves and stems from March was 12.8, 7.0 and 2.2, 39.0\% lower than parts from June. Whereas, the results of antioxidant capacity (analyzed by ABTS and FRAP assay) in bulbs and flowers from March increase around 22.2, 0.5 and $35.5,19.6 \%$ to compared bulbs and flowers from June. From the obtained results, leaves showed the highest scavenging capacities of free radical compared to the others parts. A changes of FRAP and ABTS values could affect the degree of maturity, the growing season of plants, i.e., physiological changes in the period of plant development, as well as weather conditions prevailing in the initial and final stages of plant growth. Furthermore, a decrease in the content of antioxidant capacity in the bulbs and flowers may be due to changes in the plant and its various parts during maturation or maturity of bulbs and flowers from June [44]. According to Nencini et al. [45], the level of antioxidant capacity (analyzed by FRAP assay) in leaves and bulbs of garlic (Allium sativum) were 2.1 and 1.9 folds lower than leaves and bulbs of wild garlic. Differences between the results may be due to conditions of storage, species diversity, different seasons of the collected material, and climatic conditions.

The antioxidant capacity of different parts of wild garlic is positively correlated with the content of selected bioactive compounds (triterpenoids, carotenoids, and chlorophylls) (Table 5). Triterpenoids are known for their anti-inflammatory, anticancer, and antioxidative properties [22]. The antioxidant capacity of wild garlic was positively correlated with the content of triterpenoids $\left(r^{2}=0.60\right.$ for ABTS and 0.41 for FRAP). The strongest correlation was found for ursolic acid and the ABTS method $\left(r^{2}=0.82\right)$, with a lower correlation for the FRAP method $\left(r^{2}=0.65\right)$. Carotenoids have a system of conjugated double bonds, which mainly influence their antioxidant activity. The antioxidant activity of carotenoids is used in scavenging of free radicals and counteracting oxidation, consequently reducing the risk of acute inflammation and cardiovascular problems. Chlorophyll has antioxidant properties, as well as antimutagenic and anticancer properties [31]. In our research on different parts of wild garlic, we found a positive correlation between the total content of carotenoids and antioxidant capacity $\left(r^{2}=0.95\right.$ and 0.85 for the ABTS and FRAP assay). The strongest correlation was found for carotene and the ABTS method $\left(r^{2}=0.97\right)$, with a lower correlation for the FRAP method $\left(r^{2}=0.85\right)$. Furthermore, a positive correlation between chlorophylls and antioxidant capacity $\left(r^{2}=0.91\right.$ for ABTS and $r^{2}=0.77$ for FRAP) was found in parts of wild garlic. The strongest correlation was found for chlorophylls and the ABTS method $\left(r^{2}=0.95\right)$, with a lower correlation for the FRAP method $\left(r^{2}=0.77\right)$. Mueller and Boehm [46] in their studies on antioxidant properties of $\beta$-carotene isomers and metabolites
Table 5 Correlation between antioxidant activity and all bioactive compounds*

\begin{tabular}{lll}
\hline Bioactive compounds & ABTS & FRAP \\
\hline Betulinic acid & 0.60 & 0.72 \\
Ursolic acid & 0.82 & 0.65 \\
Oleanolic acid & 0.47 & 0.28 \\
Triterpenoids & 0.60 & 0.46 \\
Neoxanthin & 0.92 & 0.81 \\
Violaxanthin & 0.35 & 0.40 \\
Lutein & 0.94 & 0.82 \\
Cryptoxanthin & 0.95 & 0.86 \\
Carotene & 0.97 & 0.85 \\
Carotenoids & 0.95 & 0.85 \\
Pheophorbide & 0.92 & 0.84 \\
Chlorophyllide & 0.91 & 0.77 \\
Chlorophyll $b$ & 0.91 & 0.78 \\
chlorophyll $a$ & 0.95 & 0.77 \\
Pheophytin & 0.86 & 0.67 \\
Chlorophylls & 0.91 & 0.77 \\
\hline
\end{tabular}

$* \alpha=0.05$

reported that $\beta$-carotenes have 10-25-fold higher antioxidant activity against ROO, and 2.5-3 times higher activity in bleaching ABTS ++ than $\alpha$-tocopherol. Qiao et al. [47] in their studies on triterpenoids of sour jujube obtained ambiguous results. Some triterpenoids showed high antioxidant capacity, which was 10-18.9-fold higher than activity of ascorbic acid, while others showed low ability to reduce free radicals. Therefore, it could be concluded that the antioxidant capacity of parts of wild garlic correlated with the presence of the triterpenoids, carotenoids, and chlorophylls and their compounds. Moreover, the high antioxidant capacity of wild garlic depended on the chemical composition of bioactive compounds and parts and perhaps influence to the inhibition of diseases associated with oxidative damage, such as coronary heart disease, stroke, and cancers [48, 49]. Wild garlic had high concentrations of antioxidant capacity and triterpenoids, carotenoids, and chlorophylls and their antioxidant properties might have a significant impact due to their chemical structures.

\section{Principal component analysis (PCA)}

The study results of leaves, bulbs, flowers, and stems of wild garlic in their triterpenoids, chlorophylls, and carotenoids were emphasized during principal component analysis. Main PCAs for the research different parts of wild garlic accounted for $95.20 \%$ of the sum variability, PC1 for $70.75 \%$ and PC2 for $24.41 \%$ are presented in Fig. 4. The results obtained in the analysis of PCA show of four clusters: 
Fig. 4 PCA map showing the relationship among triterpenoids, carotenoids, chlorophyll compounds, and antioxidant capacity of leaves, bulbs, flowers, and stems of wild garlic. $O A$ oleanolic acid, $B A$ betulinic acid, $U A$ ursolic acid, 1 neoxanthin, 2 violaxanthin, 3 all-trans-lutein, 4 13-cislutein, $5 \alpha$-cryptoxanthin, 6 $\beta$-cryptoxanthin, $7 \alpha$-carotene, 8 all-trans- $\beta$-carotene, 9 9-cis- $\beta$ carotene, 10 13-cis- $\beta$-carotene, 11 15-cis- $\beta$-carotene, carotenoids carotenoid compounds, 12 pheophorbide $a, 13$ chlorophyllide $a, 14$ chlorophyllide $b, 15$ chlorophyll $b, 16$ chlorophyll $a$, 17 pheophytin $b, 18$ pheophytin $a$, chlorophylls chlorophyll compounds

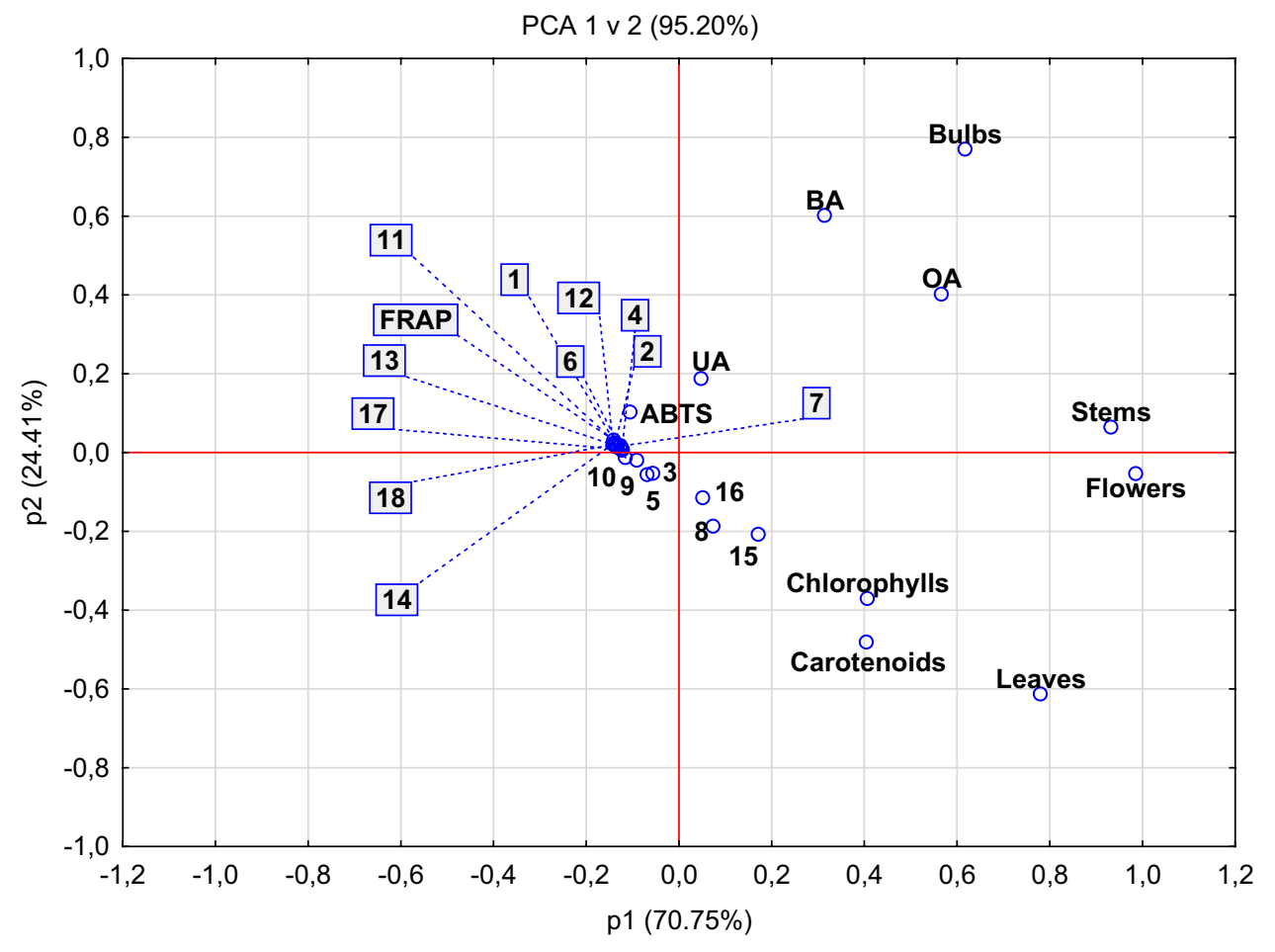

- Leaves and flowers with a higher concentration of chlorophyll compounds (chlorophylls), carotenoid compounds (carotenoids), all-trans- $\beta$-carotene (8), carotenoid compounds (carotenoids), chlorophyll $b$ (15), chlorophyll $a$ (16), and a positive correlation with the antioxidant capacity (ABTS and FRAP assay).

- Stems and bulbs with a higher concentration of positive correlation with ursolic acid (UA), oleanolic acid (OA), betulinic acid (BA), and bioactive compounds were detected.

- Neoxanthin (1), violaxanthin (2), 13-cis-lutein (4), $\beta$-cryptoxanthin (6), $\alpha$-carotene (7), 15-cis- $\beta$-carotene (11), pheophorbide $a$ (12), chlorophyllide $a$ (13), chlorophyllide $b$ (14), pheophytin $b$ (17), and pheophytin $a$ (18) with a higher correlation with antioxidant capacity ABTS and FRAP.

- 9-cis- $\beta$-Carotene (9), 13-cis- $\beta$-carotene (10), all-translutein (3), and $\alpha$-cryptoxanthin (5) with a negative correlation with different parts of wild garlic.

\section{Conclusions}

During wild garlic ripening, the content of analyzed compounds grew and was highest in June. Therefore, maturity stage had a significant influence on the antioxidant capacity and the concentration of triterpenoids, carotenoids, and chlorophylls. The different parts of wild garlic contained 18 compounds that are members of the natural plant pigments carotenoids (11) and chlorophylls (7). It was found that the leaves, from parts of wild garlic at different maturity stages, were the highest in active compounds, while bulbs exhibited the lowest content. Leaves and stems, if regularly consumed, could be a significant source of antioxidant capacity and bioactive compounds: triterpenoids, carotenoids, and chlorophylls in the diet. The bioactive compounds in leaves of A. ursinum collected in March and June display bioactive properties for humans. They could be a promising source of bioactive nutraceuticals and nutritional supplements or a food additive with potential health benefits.

Acknowledgements This publication was supported by the Wroclaw Center of Biotechnology, program The Leading National Research Centre (KNOW) for the years 2014-2018.

Author contributions Important contributions to design and preparation of the manuscript: SL. Material delivery: SL and RW. Contributions to sample and analysis experiments: SL. Analysis of the experimental data: SL. Critical revision for important intellectual content: SL, and JO. All authors helped to prepare the paper and approved the final version.

\section{Compliance with ethical standards}

Conflict of interest The authors declare no conflict of interest.

Compliance with ethics requirements All authors declare that this article does not contain any studies with human or animal subjects.

Open Access This article is distributed under the terms of the Creative Commons Attribution 4.0 International License (http://creativeco 
mmons.org/licenses/by/4.0/), which permits unrestricted use, distribution, and reproduction in any medium, provided you give appropriate credit to the original author(s) and the source, provide a link to the Creative Commons license, and indicate if changes were made.

\section{References}

1. Tomšik A, Pavlić B, Vladić J, Ramić M, Brindza J, Vidović S (2016) Ultrason Sonochem 29:502-511

2. Radulović NS, Miltojević AB, Stojković MB, Blagojević PD (2015) Food Res Int 78:1-10

3. Wu H, Dushenkov S, Ho CT, Sang S (2009) Food Chem 115(2):592-595

4. Lachowicz S, Kolniak-Ostek J, Oszmiański J, Wiśniewski R (2017) J Food Process Pres 41(1)

5. Oszmianski J, Kolniak-Ostek J, Wojdyło A (2012) J Agric Food Chem 61(1):176-184

6. Su ZY, Khor TO, Shu L, Lee JH, Saw CLL, Wu TY, Huang Y, Suh N, Yang Ch, Conney A, Wu Q, Kong A-N (2013) Chem Res Toxicol 26(3):477-485

7. Li B, Zhao H, Liu J, Liu W, Fan S, Wu G, Zhao R (2015) J Chromatograph A 1425:287-292

8. Loza-Mejía MA, Salazar JR (2015) J Mol Graph Model 62:18-25

9. Dos Reis LCR, De Oliveira VR, Hagen MEK, Jablonski A, Flôres SH, De Oliveira Rios A (2015) LWT Food Sci Technol 63(1):177-183

10. Hannoufa A, Hossain Z (2012) Biocatal Agric Biotechnol 1(3):198-202

11. Boon CS, Mcclements DJ, Weiss J, Decker EA (2010) Crit Rev Food Sci 50(6):515-532

12. Zhang $\mathrm{C}, \mathrm{Xu} \mathrm{W}$, Jin W, Shah BR, Li L, Li B (2015) Food Res Int 77:419-425

13. Lachowicz S, Oszmiański J, Pluta S (2017) Food Chem 235:234-243

14. Lin CH, Chen BH (2003) J Chromatogr A 1012(1):103-109

15. Delpino-Rius A, Eras J, Marsol-Vall A, Vilaró F, Balcells M, Canela-Garayoa R (2014) J Chromatogr A 1331:90-99

16. Farneti B, Masuero D, Costa F, Magnago P, Malnoy M, Costa G, Vrhovsek U, Mattiv F (2015) J Agric Food Chem 63(10):2750-2759

17. Re R, Pellegrini N, Proteggente A, Pannala A, Yang M, RiceEvans C (1999) Free Radical Bio Med 26(9):1231-1237

18. Benzie IF, Strain JJ (1996) Anal Biochem 239(1):70-76

19. Kolniak-Ostek J (2016) Food Chem 203:491-497

20. Naumoska K, Vovk I (2015) J Chromatogr A 1381:229-238

21. Shanmugam MK, Nguyen AH, Kumar AP, Tan BK, Sethi G (2012) Cancer Letters 320(2):158-170
22. Claude B, Morin P, Lafosse M, Andre P (2004) J Chromatogr A 1049(1):37-42

23. Caligiani A, Malavasi G, Palla G, Marseglia A, Tognolini M, Bruni R (2013) Food Chem 136(2):735-741

24. Szakiel A, PąCzkowski C, Huttunen S (2012) J Agric Food Chem 60(48):11839-11849

25. Guo S, Duan JA, Tang YP, Yang NY, Qian DW, Su SL, Shang EX (2010) J Agric Food Chem 58(10):6285-6289

26. Maoka T, Fujiwara Y, Hashimoto K, Akimoto N (2002) J Oleo Sci 51(1):1-9

27. Maurer MM, Mein JR, Chaudhuri SK, Constant HL (2014) Food Chem 165:475-482

28. Saini RK, Nile SH, Park SW (2015) Food Res Int 76:35-750

29. Deli J, Matus Z, Molnár P, Tóth G (2001) Eur Food Res Technol 213(4-5):301-305

30. Stinco CM, Benítez-González AM, Hernanz D, Vicario IM, Meléndez-Martínez AJ (2014) J Chromatogr A 1370:162-170

31. Delgado-Pelayo R, Gallardo-Guerrero L, Hornero-Méndez D (2014) Food Res Int 65:272-281

32. Cooper DA (2004) J Nutr 134(1):221S-224S

33. Lisiewska Z, Kmiecik W, Słupski J (2004) Food Chem 84(4):511-518

34. De Rosso VV, Mercadante AZ (2007) J Agric Food Chem 55(13):5062-5072

35. Azevedo-Meleiro CH, Rodriguez-Amaya DB (2004) J Food Compos Anal 17(3):385-396

36. Stahl W, Sundquist AR, Hanusch M, Schwarz W, Sies H (1993) Clin Chem 39(5):810-814

37. Milenković SM, Zvezdanović JB, Anđelković TD, Marković DZ (2012) Adv Technol 1(1):16-24

38. Suzuki K, Kamimura A, Hooker SB (2015) Mar Chem 176:96-109

39. Li X, Wang T, Zhou B, Gao W, Cao J, Huang L (2014) Food Chem 152:531-538

40. Grey B (1966) Acta Soc Bot Pol 35(2):209-224

41. Mishra SS, Mishra KN, Mahananda MR (2013) J Glob Biosci 2(1):26-30

42. Hornero-Méndez D, Mínguez-Mosquera MI (2002) J Sci Food Agric 82(13):1564-1570

43. Barla G-F, Poroch-Seritan M, Sanduleac E, Ciornei SE (2014) J Food Eng 13:349-353

44. Putnoky S, Caunii A, Butnariu M (2013) Chem Central J 7(1):21

45. Nencini C, Cavallo F, Capasso A, Franchi GG, Giorgio G, Micheli L (2007) Phytother Res 21:874-878

46. Ouis N, Hariri A (2017) Banats J Biotechnol 8(16):93-104

47. Mueller L, Boehm V (2011) Molecules 16(2):1055-1069

48. Qiao A, Wang Y, Xiang L, Zhang Z, He X (2014) Fitoterapia 98:137-142

49. Rashed K, Butnariu M (2014) Iran J Pharm Res 13(3):1073-1080 